\title{
Molecular basis for the actions of Hsp90 inhibitors and cancer therapy
}

\author{
Hiroshi Yamaki ${ }^{1}$, Motowo Nakajima ${ }^{2}$, Kumiko W Shimotohno ${ }^{1}$ and Nobuo Tanaka ${ }^{2}$ \\ Heat-shock protein 90 (Hsp90) inhibitor downregulates c-Myc expression and upregulates the expression of tumor repressor \\ proteins such as p53 and pRB, inhibiting the G1/S transition and causing G2/M arrest during cell cycle progression. \\ The cycle progression is extensively controlled by the PRB/E2F signaling pathway. E2F is released from the PRB/E2F complex \\ with the phosphorylation of pRB by cyclin-cyclin-dependent kinase (CDK) complexes. The released E2F promotes the \\ transcription of target genes involved in cell cycle progression. The PRB/E2F signaling pathway is controlled by DNA \\ methyltransferase-1 (Dnmt-1). The elevated expression of Dnmt-1 has been reported in carcinomas of the colon, lung and \\ prostate. A defect of $\mathrm{pRB}$ expression in $R b-I-$ cancer cells is caused by the aberrant methylation of $\mathrm{CpG}$ in the $R b$ promoter. \\ The Hsp90 inhibitor disrupts the Dnmt-1/Hsp90 association and upregulates pRB expression. In this review, the Hsp90 \\ inhibitors that show promise for cancer therapy are summarized.
}

The Journal of Antibiotics (2011) 64, 635-644; doi:10.1038/ja.2011.60; published online 3 August 2011

Keywords: cancer therapy; Hsp90 inhibitor; signal-transduction pathway

\section{INTRODUCTION}

Function of heat-shock protein

Heat-shock protein (Hsp) is an ubiquitous molecular chaperone distributed from bacteria to animal cells. Hsp is involved in posttranslational folding, stability and protein maturation. Hsp is an essential mediator of signal-transduction and cell cycle progression in prokaryotes and eukaryotes. Numerous Hsps including the Hsp60, Hsp70 and Hsp90 families are distributed throughout cytoplasm, mitochondria, nucleolus and cytoplasmic membrane. Human Hsp90 includes 17 genes classified as HSP90AA, HSP90AB, HSP90B and TRAP. ${ }^{1}$ Major molecular chaperones related to tumorigenesis and tumor progression are classified as Hsp90. The use of Hsp90 inhibitors for cancer therapy has recently advanced. Hsp90 inhibitors lead to misfolding of client proteins of $\mathrm{Hsp} 90$, ubiquitination and proteasome degradation. A growing number of Hsp90 client proteins (Table 1) have been shown to be important for the development, proliferation and survival of several types of cancer. Hsp90 forms complexes together with co-chaperone molecules, such as Hip, Hop, p23, Cdc37 and immunophilins (Table 2). The Hsp90 and co-chaperone complex control the binding of client proteins, enabling them to adapt to their situation. Hsp90 family proteins should be closely associated with tumorigenesis and tumor progression. Hsp90 inhibitors disturb the cellular homeostasis and inhibit the proliferation and metastasis of cancer cells. The molecular chaperone Hsp90 has emerged as an exciting target for cancer therapy in the past decade. We describe herein the molecular mechanism responsible for the action of Hsp90 inhibitors against cancer cells and review the promise of Hsp90 inhibitors for cancer therapy.

\section{HSP90'S ROLES IN TUMORIGENESIS, TUMOR PROGRESSION} AND TUMOR MAINTENANCE

The integral roles of Hsps in the multistep processes of tumorigenesis and tumor progression have been suggested. This can be understood by searching for the molecular mechanism of action of Hsp90 inhibitors. The Hsp90 molecular chaperone is expressed at high levels in a wide variety of human cancers, including melanoma, leukemia and cancers of the colon, prostate, lung and breast.

Hsp90 is amplified in cancer cells and is thought to induce their rapid proliferation. The increased expression of Hsp90 is crucial to tumorigenesis involving the loss of p53 function, and the higher expressions of the proto-oncogenes HER2 and c-Myc. ${ }^{2}$ Hsp90 inhibitors may selectively inhibit the signal-transduction pathways amplified in cancer cells. The recent progress in understanding the complex roles of Hsp90 in tumorigenesis has been made possible in the discovery of several types of Hsp90 inhibitors exhibiting antitumor effect. Hsp90 inhibitor potently inhibited cellular proliferation by inducing G1 arrest in a variety of tumor cell lines. The G1 arrest by geldanamycin (GA), a benzoquinone ansamycin antibiotic, is attributed to destabilization of the Raf- 1 protein, and to the resulting inhibition of mitogen-activated protein kinase (MAPK). GA triggers a rapid and marked decrease in the kinase activity of cyclin $\mathrm{E} /$ cyclin-dependent kinase (CDK2) complex coupled with a

${ }^{1}$ Faculty of Pharmacy, Keio University, Minato-ku, Tokyo, Japan and ${ }^{2}$ Institute of Molecular and Cellular Biosciences, University of Tokyo, Bunkyo-ku, Tokyo, Japan Correspondence: Dr H Yamaki, Faculty of Pharmacy, Keio University, Shibakoen 1-5-30, Minato-ku, Tokyo 105-8512, Japan.

E-mail: h_yamaki@castle.ocn.ne.jp

Received 26 November 2010; revised 15 March 2011; accepted 9 June 2011; published online 3 August 2011 
Table 1 Major client proteins associated with Hsp90

\begin{tabular}{|c|c|}
\hline $\begin{array}{l}\text { Hsp90 client } \\
\text { protein }\end{array}$ & Character \\
\hline v-Src & Avian Rous sarcoma viral oncogene protein=Src tyrosine kinase \\
\hline Lyn & Src family protein tyrosine kinase \\
\hline Lck & Src family protein tyrosine kinase \\
\hline Yes & $\begin{array}{l}\text { Avian sarcoma virus Y73 oncogene protein, non-receptor tyrosine } \\
\text { kinase }\end{array}$ \\
\hline $\mathrm{Fps}=\mathrm{Fes}$ & $\begin{array}{l}\text { Feline or avian sarcoma virus oncogene protein, protein tyrosine } \\
\text { kinase }\end{array}$ \\
\hline Bcr-Abl & $\begin{array}{l}\text { Breakpoint cluster region-Abelson (avian Abelson leukemia virus } \\
\text { oncogene protein) }\end{array}$ \\
\hline Raf-1 & $\begin{array}{l}\text { Serine/threonine kinase of mouse retrovirus } 3611-\mathrm{MSV} 3=\mathrm{MAP} \\
\text { kinase kinase kinase }\end{array}$ \\
\hline AKT/PKB & $\begin{array}{l}\text { v-akt murine viral oncogene homolog, serine/threonine protein } \\
\text { kinase=protein kinase } B\end{array}$ \\
\hline ErbB2 & $\begin{array}{l}\text { v-erb-b2 avian erythroblastic leukemia viral oncogene protein, } \\
\text { receptor tyrosine kinase tyrosine }\end{array}$ \\
\hline Plk-1 & Drosophila polo-like kinase 1 , serine/threonine protein kinase \\
\hline MET & $\begin{array}{l}\text { Met proto-oncogene protein, hepatocyte growth factor receptor, } \\
\text { protein tyrosine kinase }\end{array}$ \\
\hline Wee1 & $\begin{array}{l}\text { Cell cycle regulator, phosphorylate cdc } 2 \text { kinase, protein tyrosine } \\
\text { kinase }\end{array}$ \\
\hline Cdc2 & Cell division cycle $2, \mathrm{G} 1$ to $\mathrm{S}$ and $\mathrm{G} 2$ to $\mathrm{M}$ cell cycle regulator \\
\hline Cdc4 & $\begin{array}{l}\text { Bind directly to cyclin E, targets cyclin E for ubiquitin-mediated } \\
\text { degradation }\end{array}$ \\
\hline Cdc6 & $\begin{array}{l}\text { A protein essential for a regulator at the early steps of DNA } \\
\text { replication }\end{array}$ \\
\hline Dnmt-1 & DNA cytosine-5-methyltransferase \\
\hline Survivin & $\begin{array}{l}\text { Baculoviral inhibitors of apoptosis protein=inhibitors of caspase } \\
\text { family proteases }\end{array}$ \\
\hline Mutant p53 & $\begin{array}{l}\text { A mutated tumor repressor protein, loss of the function } \\
\text { of transcription factor }\end{array}$ \\
\hline C-Myc & $\begin{array}{l}\text { Proto-oncogene protein of avian myelocytomatosis virus MC29 } \\
\text { oncogene }\end{array}$ \\
\hline hTERT & $\begin{array}{l}\text { Human telomerase reverse transcriptase, telomerase is related } \\
\text { to cells survival }\end{array}$ \\
\hline MOK & A member of the mitogen-activated protein kinase superfamily \\
\hline MAK & $\begin{array}{l}\text { Male germ-cell-associated kinase, nuclear Cdc2-related kinase } \\
\text { or MAPKK }\end{array}$ \\
\hline MRK & $\begin{array}{l}\text { A member of the MAPKKK family of signal-transduction } \\
\text { molecules }\end{array}$ \\
\hline $\begin{array}{l}\text { DNA } \\
\text { polymerase } \alpha\end{array}$ & DNA polymerase for mammalian chromosomal DNA replication \\
\hline $\begin{array}{l}\text { Estrogen } \\
\text { receptor }\end{array}$ & Likely to develop tumors with high expression \\
\hline $\begin{array}{l}\text { Androgen } \\
\text { receptor }\end{array}$ & $\begin{array}{l}\text { Likely to develop breast cancer, prostate cancer with high } \\
\text { expression }\end{array}$ \\
\hline HIF- $1 \alpha$ & $\begin{array}{l}\text { Hypoxia-inducible factor- } 1 \alpha \text {, a family of proteins responsible for } \\
\text { cellular oxygen deficiency }\end{array}$ \\
\hline SV40 large & A potent oncogene able to transform many cell types, binds to \\
\hline T antigen & the viral replication origin and promotes the SV40 replication \\
\hline $\begin{array}{l}\text { SV40 small } \\
\text { T antigen }\end{array}$ & $\begin{array}{l}\text { Promotes the efficient replication of genomic DNA, accelerating } \\
\text { the progression of the } S \text { phase }\end{array}$ \\
\hline $\begin{array}{l}\text { EBV nuclear } \\
\text { antigen }\end{array}$ & $\begin{array}{l}\text { EBNA, EBNA2, EBNA5, EBNA3A and EBNA3C are essential for } \\
\text { transformation to Burkitt's lymphoma, and so on }\end{array}$ \\
\hline
\end{tabular}

Abbreviation: EBNA, Epstein-Barr virus nuclear antigen.

decline in CDK2 associated with cyclin E, accompanied by the inhibition of CDK4 kinase activity and the inhibition of $\mathrm{pRB}$ hyperphosphorylation. ${ }^{3}$
Table 2 Major co-chaperone proteins associated with Hsp90

\begin{tabular}{ll} 
Co-chaperone molecules of Hsp90 \\
\hline Hip & Mammalian Hsp70-interacting protein \\
Hop & Mammalian Hsp70/Hsp90-organizing protein \\
p23 & Selectively destabilizes steroid receptors \\
Cdc37 & A regulator of Hsp90 function to bind clients \\
Immunophilins & Cyclophilin A and FKBP12: cyclophilin A (Cyp40) and \\
& FKBP12 are the major targets of the immunosuppressive \\
& agents, CsA and FK506, respectively. The complex of Cyp40 \\
& and FKBP51 inhibits the function of NFAT
\end{tabular}

Abbreviations: CsA, cyclosporin A; Hsp, Heat-shock protein; NFAT, nuclear factor of activated T cell.

\section{HSP9O INHIBITORS AND SIGNALING PATHWAYS}

The rapid proliferation of cancer cells must be attributable to an unusual signaling pathway. A number of oncogene, proto-oncogene and tumor suppressor proteins are reportedly associated with Hsp90 or Hsp90-cochaperone complexes. GA was first identified as an Hsp90 inhibitor. ${ }^{4}$ X-ray-diffraction studies have demonstrated Hsp90-GA complexes. ${ }^{5}$ It is important to understand the biology of Hsp90 chaperone at the molecular level before proceeding to the development of Hsp90 inhibitors.

\section{Conformational cycle of Hsp90 chaperone}

Hsp90 operates as a dimer in a conformational cycle driven by ATP binding and hydrolysis at the $\mathrm{N}$ terminus. ${ }^{6}$ The transient $\mathrm{N}$-terminal dimerization of Hsp90 has been investigated under the assumption that the C-terminal interface is stably dimerized. Using a fluorescencebased single-molecule assay, kinetic analysis of the $\mathrm{N}$ - and C-terminal dimerizations was performed. Surprisingly, the C-terminal dimer opens and closes with fast kinetics. ${ }^{7}$ The middle domain of Hsp90 (Hsp90M) acts as a discriminator between different types of client proteins. $^{8}$

GA interacts with the N-terminal ATP-binding domain of Hsp90, inhibiting its ATPase activity, and causes the release of the client protein. ${ }^{9}$ Novobiocin disrupts both $\mathrm{N}$ - and C-terminal nucleotide binding. ${ }^{9}$ Cisplatin is a selective C-terminal nucleotide competitor. ${ }^{9}$ These results indicate that the conformation of the middle domain is affected by an elaborate mechanism involving the $\mathrm{C}$ - and $\mathrm{N}$-terminus conformation of Hsp90. GA and novobiocin are important tools for the initial characterization of Hsp90 function, but do not represent clinically viable compounds.

The client proteins of Hsp90 include v-Src, Lyn, Yes, Fps, Lck, Bcr-Abl, Raf-1, ATK/protein kinase B (PKB), ErbB2/HER2/Neu, hypoxia-inducible factor- $1 \alpha$, Plk-1, MET, Wee1, CDC2, CDC4, CDC6, CDK4, DNA methyltransferase-1 (Dnmt-1), steroid hormone receptors (estrogen and androgen receptors), survivin, telomerase human telomerase reverse transcriptase (hTERT), mitogen-activated protein kinase (MOK), male germ-cell-associated kinase (MAK), MRK, SV40 super T, large T, small T antigen, EBV nuclear antigen, mutant p53, c-Myc and DNA polymerase $\alpha$. The major client proteins of Hsp90 involved in the signaling pathways are illustrated in Table 1. The viral oncogenic partner proteins of $\mathrm{pRB}$, including human papilloma-coded protein E7, adenovirus E1A-encoded protein and SV40 large T antigen associated with pRB, deregulate the cell cycle progression and the cellular proliferation of neoplasia. ${ }^{10}$ These viral oncogenic partner proteins of pRB preferentially bind to underphosphorylated gene products of the retinoblastoma family gene products. The association of these viral oncogenic partner proteins 
of $\mathrm{pRB}$ causes the dissociation of the pRB/E2Fcomplex, and the released E2F upregulates a large number of genes essential for cell cycle progression. The $\mathrm{pRB} / \mathrm{E} 2 \mathrm{~F}$ complex releases E2F upon the phosphorylation of pRB by cyclin E/CDK2 and cyclin A/CDK2 complexes (Figure 1). Overexpression of cyclin $\mathrm{E}$ in tumor cells bypasses the feedback expressions of cyclin D/CDK4 and CDK6/ pRB. ${ }^{11}$ When the $\mathrm{pRB}$ binding to the partner proteins is eliminated by a $\mathrm{pRB}$ mutation, its partner proteins are activated and promote cell cycle progression. The major partner proteins of pRB involved in cell cycle progression are Myc and E2F. The amino-terminal domains of $\mathrm{c}$ Myc and N-Myc mediate binding to the pRB carboxyl-terminal domain. ${ }^{12}$ E2F contains the carboxyl-terminal domains that bind to pRB family proteins. Targeting the c-Myc expression is an important objective for cancer chemotherapy. ${ }^{13}$ Hsp90 inhibitors downregulate c-Myc expression. ${ }^{14,15}$ The c-Myc protein bound to TFIIIB, a RNA polymerase III-specific general transcription factor, directly activates pol III transcription, thereby stimulating ribosomal RNA production. ${ }^{16,17}$ The tumor suppressors $\mathrm{p} 53$ and pRB repress TFIIIB expression. ${ }^{17}$ The c-Myc protein itself is assumed to be necessary for c-Myc expression. ${ }^{18}$ The c-Myc expression is under self-control. Hsp90 inhibitor causes the degradation of the client protein $\mathrm{c}-\mathrm{Myc}$, and consequently downregulates the synthesis of mRNA, ribosomal RNA and low-molecular-weight RNA.

\section{MicroRNA studies and Hsp 90 inhibitor}

Humans have 800-1000 microRNAs (miRNAs), and these miRNAs are thought to regulate a significant fraction (more than $30 \%$ ) of all

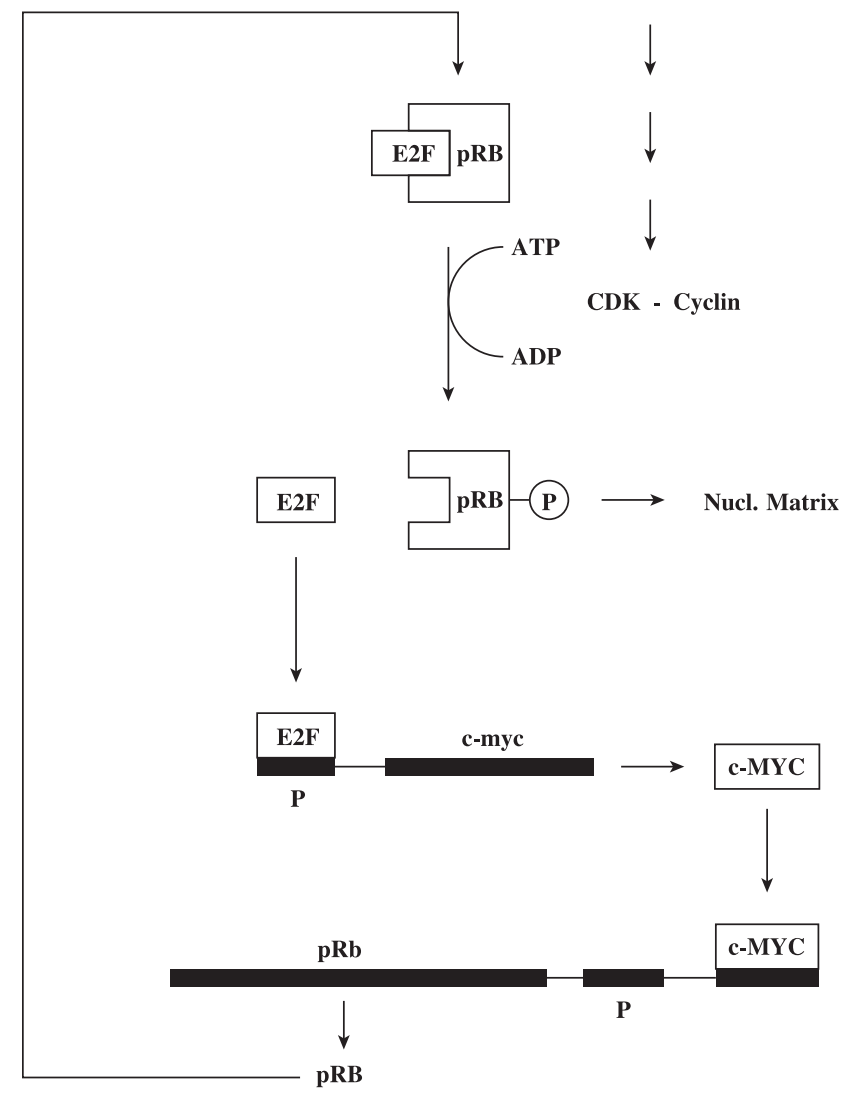

Figure 1 E2F-pRB signaling pathway. CDK: cyclin-dependent kinase; c-MYC: avian myelocytomatosis MC29 virus gene product; E2F: factor binding to adenovirus E2 gene promoter; $\mathrm{P}$ : promoter; circled $\mathrm{P}$ : phosphate; $\mathrm{pRB}$ : retinoblastoma gene product; Nucl Matrix: nuclear matrix. protein-coding genes. ${ }^{19}$ miRNA, a form of small non-coding RNA, modulates cell cycle-dependent transcription during normal or tumoral proliferation through a complex interplay between itself and c-Myc or E2F family members. ${ }^{20,21} \mathrm{E} 2 \mathrm{~F}$ transcription factors are classified into eight groups, E2F-1-E2F-8. ${ }^{21}$ The expression of E2F is modulated by miRNAs. The tumor suppressor miR-34a regulates the p53 pathway and downregulates c-Myc expression. ${ }^{22}$ Let-7 miRNAs function as tumor suppressors by negatively regulating the expression of multiple oncogenes including ras and $m y c .{ }^{23}$ Argonate proteins are associated with processing bodies and stress granules of cytoplasmic ribonucleoprotein complexes, which regulate gene expression. Argonates are effectors of RNA interference. Hsp90 is required for the efficient targeting of hAgo2 to processing bodies and stress granules. Hsp90 inhibitor is associated with reduced miRNA and short interfering RNA-dependent gene silencing. ${ }^{24}$

Below, we describe several signaling pathways involving Hsp90.

Connexin $43(\mathrm{Cx} 43)$ is essential for the survival of cells. The expression of $\mathrm{Cx} 43$ is increased in ras-transformed cells, being enhanced by the Ras-Raf-MAPK pathway (Figure 2). The c-MycHsp90 complex formed in Ras-transformed cells binds the AGTTCAATCA sequence as the Cx43 promoter element. The Hsp90 inhibitor suppresses the c-Myc-Hsp90 complex binding to the Cx43 promoter, and inhibits the $\mathrm{Cx} 43$ promoter activity. ${ }^{25}$

The co-expression of $\mathrm{Bcl} 2$ and $\mathrm{c}-\mathrm{Myc}$ efficiently antagonizes the effects of p53 on G1 arrest and apoptosis. ${ }^{26}$

A set of molecular chaperones Hsp90 and their co-chaperone CDC37 complex reportedly associate specifically with MOK, a member of the MAPK superfamily, and casein kinase 2 controls multiple kinases by phosphorylating the molecular chaperone CDC37. The Hsp90 inhibitors disrupt these pathways. ${ }^{27,28}$

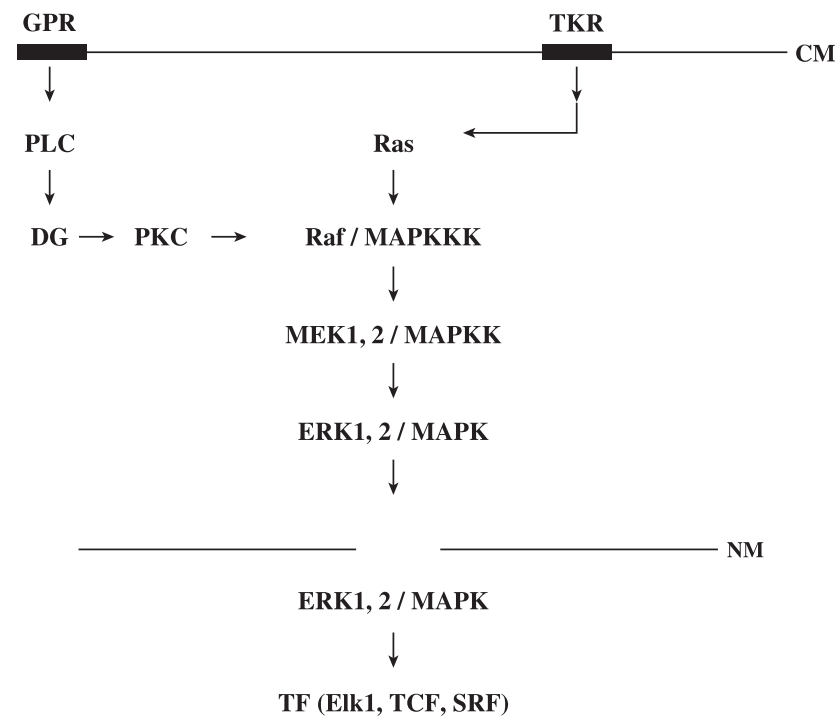

Figure 2 Ras-Raf-MAPK signaling pathway. CM: cytoplasmic membrane; DG: diacylglycerol; EIK1: ternary complex factor; GPR: G-protein receptor; MAPK: mitogen-activated protein kinase; MAPKK: MAPK kinase; MAPKKK: MAPKK kinase; $M E K=E R K=M A P K$; NM: nuclear membrane; PLC: phospholipase C; PKC: protein kinase C; Ras: rat sarcoma gene product p21-GTP binding protein; Raf: rat fibrosarcoma gene product p74 ser/thr kinase; SRF: serum response factor; two molecules SRF and one molecule TCF or EIK1 form trimer; TCF: ternary complex factor; TF: transcription factor; TKR: tyrosine kinase receptor. 


\section{CHROMOSOMAL DNA DUPLICATION AND CELL DIVISION}

Eukaryotic genomes consist of multiple replicons. The human autonomous replication sequence (ARS/origin) was identified as a 36-bp determinant. ${ }^{29} \mathrm{An}$ internal $20 \mathrm{bp}$ within the 36 -bp consensus sequence is sufficient to act as a core origin element. Moreover, the origin activity in the tumor-transformed cells is two- to threefold higher than that of normal cells..$^{30}$ In chromosomal DNA replication, a plausible supermolecular assembly, the origin recognition complex, and the replisomes are thought to function in DNA replication initiation and the elongation of the DNA strands, respectively. The cell cycle starts from a Go quiescent state. The entry of G1 into the $S$ phase is accompanied by a sharp rise in DNA polymerase (Pol $\alpha$ ), a client protein of Hsp90. GA inhibits DNA replication with the partially purified Pol $\alpha$, but the highly purified Pol $\alpha$ is refractory to GA. ${ }^{31}$ This suggests that GA interacts with Hsp90 and disrupts the Hsp90/Pol $\alpha$ complex.

Inhibition of association of $\mathrm{pRB}$ with nuclear matrix by $\mathrm{Hsp90}$ inhibitor

GA inhibits the G1/S transition and causes G2/M arrest during cell cycle progression (Figure 3), ${ }^{14,15}$ and c-Myc expression along with the
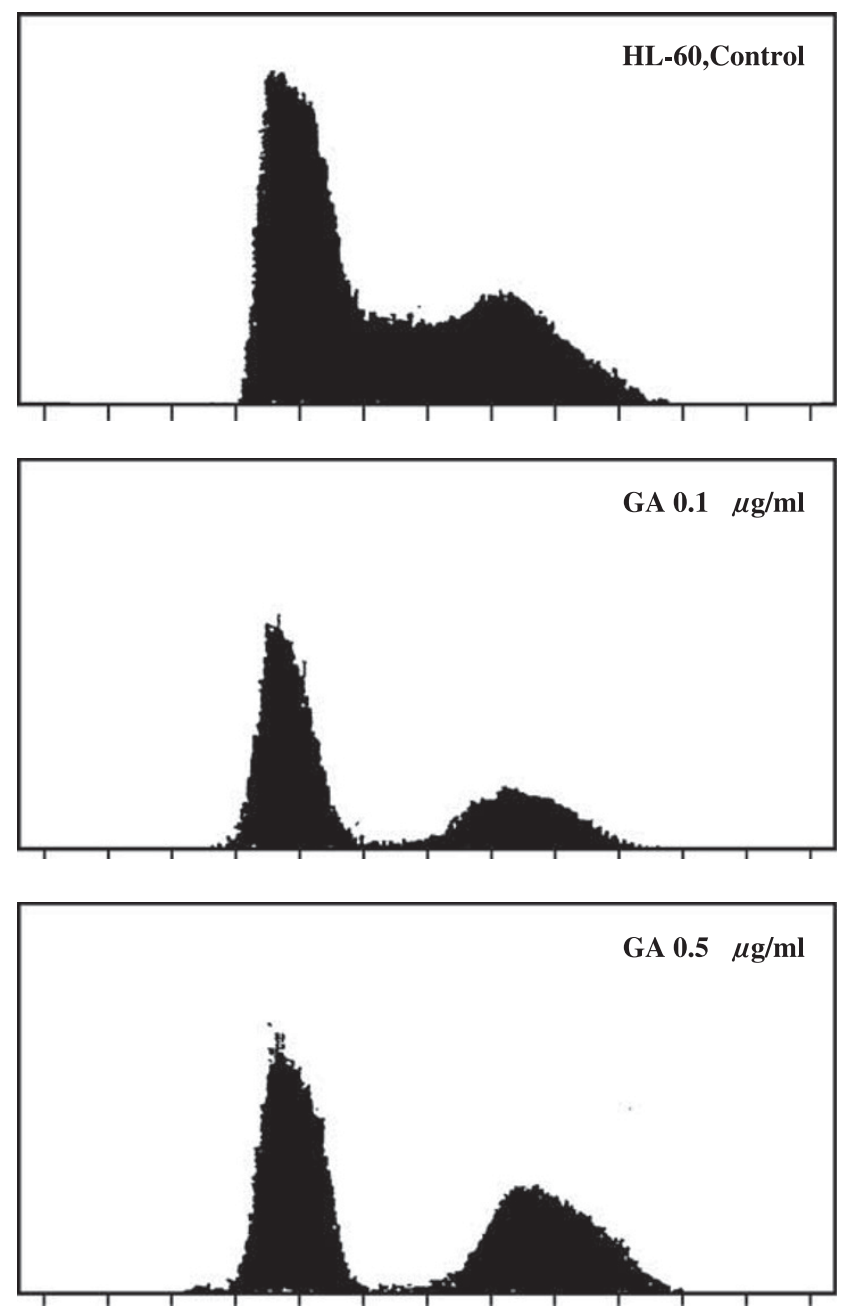

Figure 3 Geldanamycin-induced inhibition of cell cycle progression in HL-60 cells. L-60 cells cultured at an initial density of $1.5 \times 10^{5}$ cells per $\mathrm{ml}$ after exposure to 0.1 or $0.5 \mu \mathrm{g} \mathrm{ml}^{-1} \mathrm{GA}$ for $20 \mathrm{~h}$ were compared with control cells using flow cytometry. GA, geldanamycin. upregulation of p53 and pRB expressions. The association between pRB and the nuclear matrix was inhibited by GA (Figure 4). ${ }^{14}$ Lamin A, a major protein in the nuclear matrix, may be involved in the association between $\mathrm{pRB}$ and the nuclear matrix. ${ }^{14,32}$ The G2/M arrest induced by $\mathrm{Hsp} 90$ inhibitor may be attributable to inhibition of the association between $\mathrm{pRB}$ and the nuclear matrix, presumably resulting in the inhibition of chromosome segregation and subsequent cell division.

\section{A POSSIBLE MODEL FOR THE INHIBITION OF CELL CYCLE PROGRESSION BY HSP9O INHIBITORS}

Dnmt-1 controls the pRB/E2F signaling pathway

We propose here a possible model of the molecular mechanism by which Hsp90 inhibitor inhibits c-Myc expression and upregulates pRB expression. Dnmt-1 expression is regulated by the $\mathrm{pRB} / \mathrm{E} 2 \mathrm{~F}$ signaling pathway $^{33}$ (Figure 5). E2F binds to the promoter of Dnmt-1 and promotes the expression of Dnmt-1. Dnmt- 1 catalyzes the transfer of methyl groups to cytosine in $\mathrm{CpG}$ dinucleotides. The methylation of CpG in the $R b$ promoter suppresses pRB expression. The elevated expression of Dnmt-1 has been shown in carcinomas of the colon, lung and prostate. The defect of pRB expression in $R b-/-$ cancer cells is caused by the aberrant methylation of $\mathrm{CpG}$ in the $R b$ promoter. ${ }^{33}$ Histone deacetylase (HDAC) inhibitor promotes ubiquitin-dependent proteasome degradation of Dnmt-1 by Hsp90 disruption. ${ }^{34}$ Dnmt inhibitors markedly decrease vessel formation and tumor cell growth. ${ }^{35}$ HDAC and Dnmt-1 inhibitor should be promising for cancer therapy.

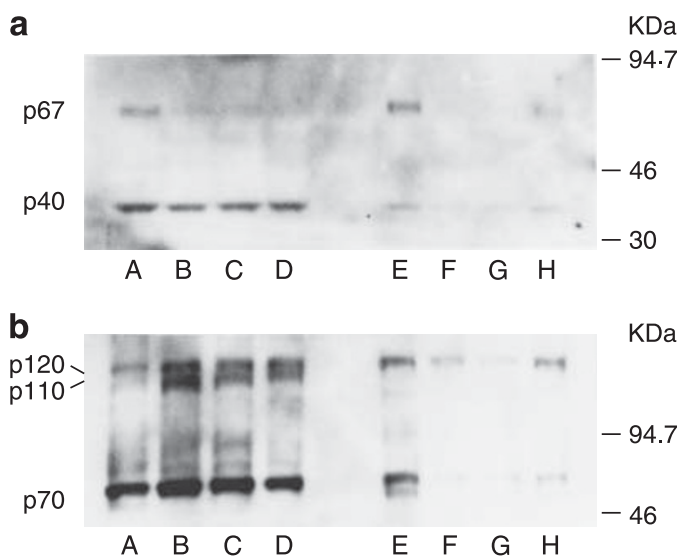

Figure 4 Effect of geldanamycin on the expressions of c-MYC, p40, pRB and p70, and their associations with the nuclear matrix in HL-60 cells. (a) Effect of geldanamycin on the expressions of c-MYC and p40 and their associations with the nuclear matrix in HL-60 cells. Proteins were transferred from a polyacrylamide gel to a nitrocellulose sheet and analyzed using western blotting. c-MYC and a 40-kDa protein crossreactive with antihuman C-MYC monoclonal antibody are indicated by p67 and p40, respectively. Lanes $A$ to $D$ indicate nuclear extracts, and lanes $B$ to $H$ indicate nuclear matrices from $\mathrm{HL}-60$ cells. Lanes $\mathrm{A}$ and $\mathrm{E}$ : control; lanes $\mathrm{B}$ and $F$ : $1 \mu \mathrm{g} \mathrm{ml}^{-1} \mathrm{GA}$; lanes $C$ and $G$ : $0.2 \mu \mathrm{g} \mathrm{ml}^{-1} \mathrm{GA}$; lanes $D$ and $H$ : $0.04 \mu \mathrm{g} \mathrm{ml}^{-1} \mathrm{GA}$. The MWs of the marker proteins are expressed in $\mathrm{kDa}$. GA: geldanamycin. (b) Effect of geldanamycin on the expressions of pRB and p70 and their associations with the nuclear matrix in HL-60 cells. Proteins were transferred from a polyacrylamide gel to a nitrocellulose sheet and analyzed using western blotting. pRB and a 70-kDa protein crossreactive with anti-pRB monoclonal antibody are indicated by p110 (underphosphorylated pRB) and p120 (hyper-phosphorylated pRB), respectively. Lanes $A$ to $D$ indicate nuclear extracts, and lanes $B$ to $H$ indicate nuclear matrices from HL-60 cells. Lanes $A$ and $E$ : control; lanes $B$ and $F: 1 \mu \mathrm{gl}^{-1}$ $\mathrm{GA}$; lanes $\mathrm{C}$ and $\mathrm{G}: 0.2 \mu \mathrm{g} \mathrm{ml}^{-1} \mathrm{GA}$; lanes $\mathrm{D}$ and $\mathrm{H}: 0.04 \mu \mathrm{g} \mathrm{ml}^{-1} \mathrm{GA}$. The MWs of the marker proteins are expressed in $\mathrm{kDa}$. GA: geldanamycin. 


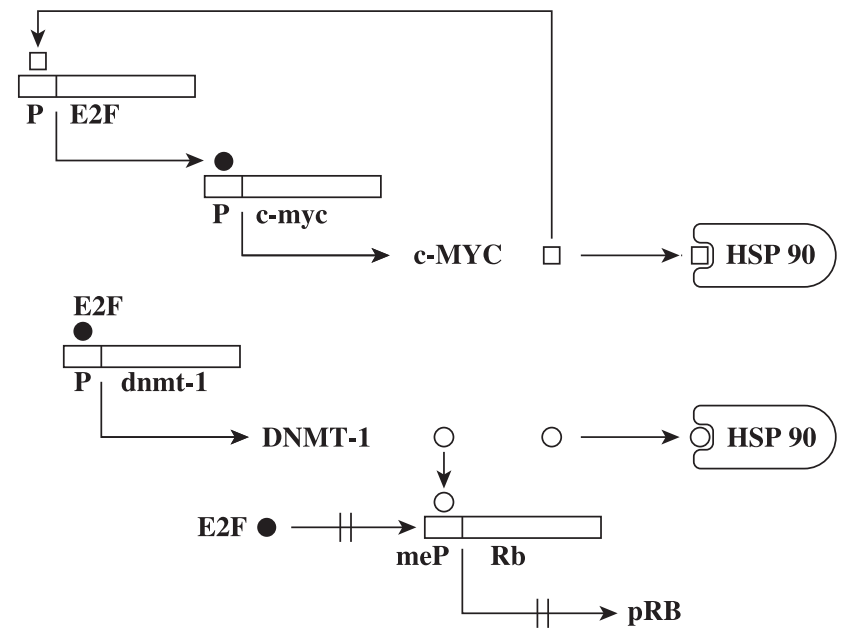

b
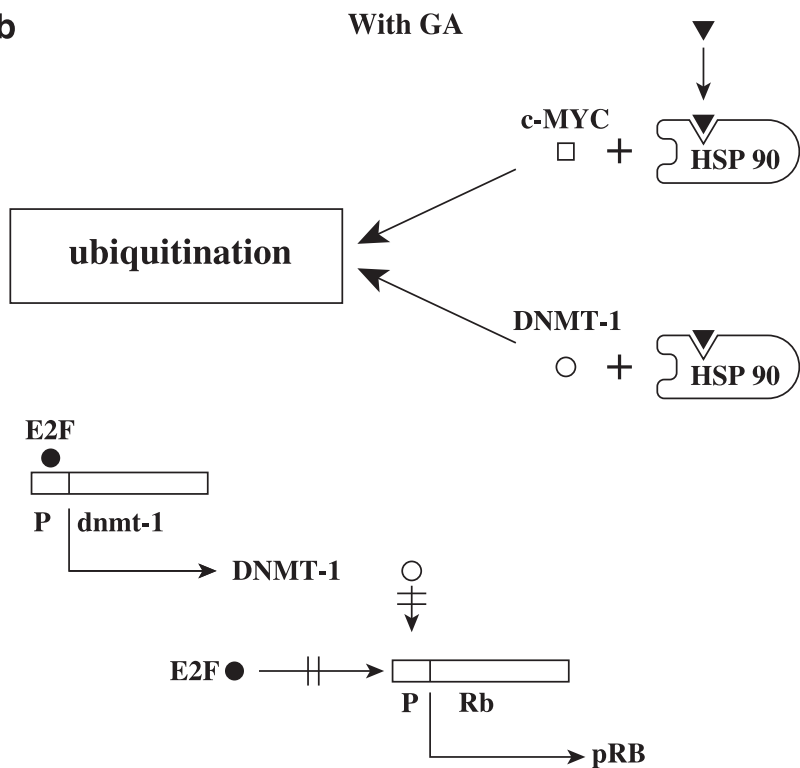

Figure $5 \mathrm{~A}$ model for the regulation of $\mathrm{c}-\mathrm{MYC}$ and $\mathrm{pRB}$ expression in the E2F/pRB signaling pathway and the effect of geldanamycin on this pathway. (a) A model for the regulation of c-MYC and pRB expression. (b) A model for the regulation of c-MYC and pRB expression in the presence of GA. DNMT-1, dnmt-1: DNA methyltransferase-1; GA: geldanamycin; meP: methylated promoter.

Dnmt-1 controls the c-Myc expression and the upregulation of p53 The molecular mechanism for the downregulation of c-Myc expression and the upregulation of p53 by GA in L5178Y cells ${ }^{15}$ can be explained in four steps (Figure 6). The Hsp90 inhibitor inactivates Hsp90 and destabilizes its client c-Myc protein (Figure 6a). The p53 promoter region from -96 to -41 contains nuclear factor- $\kappa \mathrm{B}$ and $\mathrm{c}-\mathrm{Myc}$ binding sites. ${ }^{36}$ In addition, nuclear factor- $\kappa \mathrm{B}$ binding to the p53 promoter causes the upregulation of p53 expression (Figure 6c). Wild-type p53 suppresses c-Myc expression (Figure 6d). Wild-type p53 binds to $\mathrm{p} 21$ (CDK inhibitor) promoter, triggering the expression of p21 and inhibiting G1/S transition during cell cycle progression. c-Myc directly regulates the expression of AP4 via CACGTG motifs in the first intron of the AP4 gene, and AP4 directly represses p21 expression by occupying four CAGCTG motifs in the $p 21$ promoter

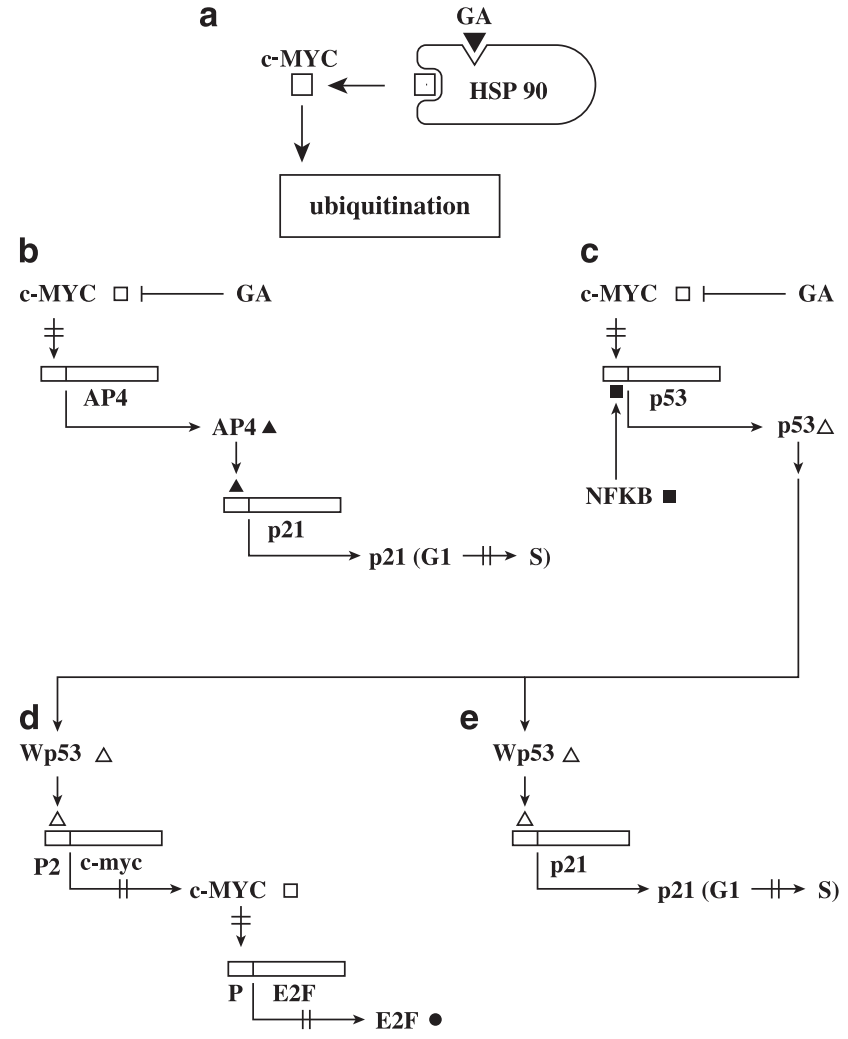

Figure $6 \mathrm{~A}$ model for the regulation of $\mathrm{c}-\mathrm{MYC}$ and p53 expression and the effect of geldanamycin (GA) on c-MYC and p53 expression. (a) A model for the degradation of $\mathrm{c}-\mathrm{MYC}$ in the presence of GA. (b) A model for the expression of p21 in the presence of GA. (c) A model for the expression of p53 in the presence of GA. (d) A model for the the inhibition of E2F expression by wp53. (e) A model for the expression of p21 by wp53. AP4: activator protein 4; NF-кB: NF-kB; p21: p21cdk inhibitor; wp53: wild-type p53.

(Figure 6b). ${ }^{37}$ These findings indicate that c-Myc protein downregulates p21 expression (Figure 6e).

HSP9O INHIBITORS ARE PROMISING FOR CANCER THERAPY Our interest lies in how to exploit the therapeutic potentials of Hsp90 inhibitors. Numerous Hsp90 inhibitors have been reported since GA was first identified as an Hsp90 inhibitor in 1994. The molecular mechanism responsible for the signaling pathway involved in Hsp90 action has been identified by exploring the mechanism of Hsp90 action.

17-AAG (17-allylamino-17-demethoxy GA) is currently being examined in Phase 3 clinical trials. 17-AAG is less toxic than GA and depletes some proteins involved in phosphoinositide 3-kinase (PI3K)/Akt signaling, such as ErbB2, epidermal growth factor receptor (EGFR) and phosphorylated AKT. ${ }^{38}$ 17-AAG decreases a group of Myc-regulated mRNAs and increases the mRNA expression of Hsp90 $\beta$, Hsp72, Hsp70, Hsp47 and Hsp27. ${ }^{39}$ The major molecular chaperones Hsp90, Hsp70 and Hsp60 interact with newly synthesized polypeptides, and maintain the proteins in unfolded states that are suitable for translocation across the membrane. The nuclear translocation of heparanase is abolished by GA and 17-AAG in HL-60 cells, indicating that Hsp90 is involved in the nuclear translocation of heparanase. ${ }^{40}$

17-Dimethyaminoethylamino-17-demethoxy GA has been shown to be active against multiple myeloma in a synergistic manner when 
administered in combination with the Akt inhibitor perifosine. ${ }^{41}$ Dimethyaminoethylamino-17-demethoxy GA also acts in synergy with the effect of radiation therapy against non-small-cell lung carcinoma by interfering with base excision and ATM-mediated DNA repair. ${ }^{42}$ DMGA-N-oxide, a novel cell-impermeable Hsp90 inhibitor, was reported to show a dramatic impact on the metastatic phenotype of the lung colonization of melanoma cells and be related to the hepatotoxic property of benzoquinone ansamycins. ${ }^{43}$

The O-carbamoylmethyloxime derivative of radicicol, KF25706, inhibits v-Src- and k-Ras-activated signaling. ${ }^{44,45}$

Macbecin ${ }^{46}$ and its non-quinone compound that target Hsp90 have been reported, ${ }^{47}$ indicating that the quinone moiety of macbecin is not a prerequisite for Hsp90 inhibition. The non-quinone derivative of macbecin has significantly improved the binding affinity to Hsp90 in vitro.

The carbazol-4-one benzamide derivatives, SNX-2112 and SNX-5422, exhibit potent antitumor activities against HER kinasedependent cancers. These compounds cause HER2 degradation and the regression of HER2-dependent xenografts, potently inhibiting tumor cell growth, angiogenesis and osteoclastogenesis in multiple myelomas and other hematological tumors by abrogating signaling via Akt and ERK. ${ }^{48,49}$

Two 17-AAG formulations, tanespimycin and IPI-504, are Hsp90 inhibitors. IPI-504 has been found to display antitumor activity against pancreatic cancer xenografts and is a promising compound against gastrointestinal stromal tumors of platelet-derived growth factor receptor- $\alpha$ mutants. ${ }^{50}$

Genistein, an isoflavone, inhibits EGFR tyrosine kinase, ${ }^{51}$ and also inhibits the Hsp90 deacetylase (HDAC6)-Hsp90 co-chaperone function, which downregulates the expression of androgen receptor in androgen-dependent prostate cancer cell lines. ${ }^{52}$

Quercetin, a flavonoid, inhibits cancer cells that over-express ErbB2 (Her-2/neu) trans-membrane tyrosine kinase and downregulates the downstream PI3K-Akt signaling pathway. ${ }^{53}$

Novobiocin binds to the C-terminal domain of Hsp90 and disrupts the Bcr-Abl/Hsp90 complex. ${ }^{54,55}$ The novobiocin derivatives, 4TCNA and 7TCNA, destabilize Raf-1, HER2 and CDK4 in human cancer cells. ${ }^{56}$

The Hsp90 inhibitor STA-9090 inhibits Kit-dependent and -independent malignant mast cell tumors. ${ }^{57}$

The pyrazole-based compounds, CCT018159 and 3,4-diarylpyrazole resorcinol, and their amide derivatives, VER-49009 and VER-50589, have been reported to be Hsp90 inhibitors. Consistent with Hsp90 inhibition, these analogs cause the induction of Hsp72 and Hsp27 alongside the depletion of $\mathrm{Hsp} 90$ client proteins, including $c$-Raf and b-Raf. The cellular potency of these analogs is independent of $\mathrm{NAD}(\mathrm{P}) \mathrm{H}$ quinone oxidoreductase 1/DT-diaphorase and P-glycoprotein expression. ${ }^{58}$ Hydroquinone ansamycins converted with quinone oxidoreductase 1 lead to a greater Hsp90 inhibitory activity and reduced toxicity.

The isoxazole derivatives NVP-AUY922, ${ }^{59}$ PU-H71, ${ }^{60}$ CUDC- $305^{61}$ and BIIB021 (CNF2024) $)^{62}$ are Hsp90 inhibitors that have been tested clinically. 17-AAG and other benzoquinone ansamycins are inactive in P-glycoprotein/MRP-1-expressing tumors, but BIIB021 is active independently of NQO1/DT-diaphorase and P-glycoprotein expression. BIIB021, which can be orally administered, decreases Hodgkin's lymphoma cell viability at low nanomolar concentrations in synergy with doxorubicin and gemcitabine. ${ }^{63}$ The use of an inhibitor of PI3K/ Akt/mTOR (mammalian target of rapamycin: ser/thr kinase signaling pathway), such as NVP-BEZ235, and targeting Hsp90 chaperone improves the efficacy of rapamycin against hepatocellular carcinoma. ${ }^{64,65}$
Hsp90 inhibitors target Raf-1. The disruption of the Raf-1/Hsp90 complex by GA results in the loss of Raf-1-Ras associations. ${ }^{66} \mathrm{PU}-\mathrm{H} 17$ downregulates components of the Ras/Raf/MAPK pathway and G2/M phase progression and induces the degradation of activated Akt and Bcl-Abl inducing apoptosis. PU-H17 shows potent antitumor effects against triple-negative breast cancers (defined by the absence of estrogen, progesterone and HER2 receptors). ${ }^{60} \mathrm{Hsp} 90$ inhibitors are thought to downregulate Ras expression and also be active against triple-negative breast cancers. PI3K and MAPK kinase inhibitors are active against k-Ras G12D, PIK3CA and H1047R murine lung cancers. ${ }^{67}$ The combined use of NVP-BEZ235 and ARR-142886, an MAPK kinase inhibitor, showed marked synergy in shrinking k-Rasmutant murine lung cancers. ${ }^{67}$ Hsp90 has an important role in 3-phosphoinositide-dependent protein kinase-1-Akt signaling pathway. ${ }^{68} 3$-Phosphoinositide-dependent protein kinase-1 binds Hsp90, and Hsp90 inhibitor causes proteasome-dependent degradation of 3-phosphoinositide-dependent protein kinase-1.

\section{Antibodies against tumor-specific cell surface antigens}

Antibodies against tumor-specific cell surface antigens could be a favorable means of targeting cancer cells. Transtuzumab, a monoclonal antibody directed against p95-HER2, has been proven to be effective in the treatment of Her2-overexpressing breast cancer. ${ }^{69}$ IPI-504 is a highly soluble small-molecule inhibitor of Hsp90. Combination of IPI-504 with transtuzumab significantly enhances tumor growth delay. ${ }^{70}$ Combination of IPI-504 with lapatinib also enhances tumor growth delay. ${ }^{70}$

The provirus integration site for Moloney murine leukemia virus tumor-specific cell surface antigens (PIM-1) is a proto-oncogene that encodes ser/thr kinase with multiple cellular functions. Overexpression of PIM-1 has a critical role in the progression of prostatic and hematopoietic malignancies.

PIM-1-specific monoclonal antibody suppresses human and mouse tumor growth by decreasing PIM-1 levels, reducing Akt phosphorylation and activating apoptosis. ${ }^{71}$

\section{Heparanase is involved in tumor metastasis}

Heparanase displays pleiotropic effects on cancer progression. Heparanase cleaves carbohydrate chains of heparan sulfate proteoglycans (HS chains), which are an important component of the extracellular matrix. Hsp90 is involved in nuclear translocation and angiogenesis through the degradation of HS chains in the extracellular matrix on the cell surface. Heparanase is involved in angiogenesis through the direct induction of Cox-2 (cyclo-oxygenase-2, prostaglandin endoperoxide synthase or prostaglandin $\mathrm{H}$ synthase). Cyclo-oxygenase-2 induces vascular endothelial growth factor and basic fibroblast growth factor and is involved in neovascularization. ${ }^{72}$ Heparanase is involved in tumor metastasis by inducing endothelial cell migration by the activation of the Akt/PKB signaling pathway in a manner that is independent of its endoglycosidase activity. The combination of Hsp90 inhibitor and heparanase inhibitors, such as suramin, ${ }^{73}$ could be a promising treatment for blocking cancer metastasis.

\section{HSP9O INHIBITORS IN VARIOUS STAGES OF CLINICAL TRIALS}

A large multi-faced Phase 1 program was designed to evaluate the pharmacokinetics, safety, efficacy and targeted biological activity of a once-daily oral dose. The maximum-tolerated dose identified in Phase 1 trials is typically used to determine the dose level for Phase 2 and 3 trials. Several Hsp90 inhibitors are currently being evaluated. The chemical structures of major Hsp90 inhibitors under clinical trials are shown ${ }^{74}$ (Figure 7 ). 

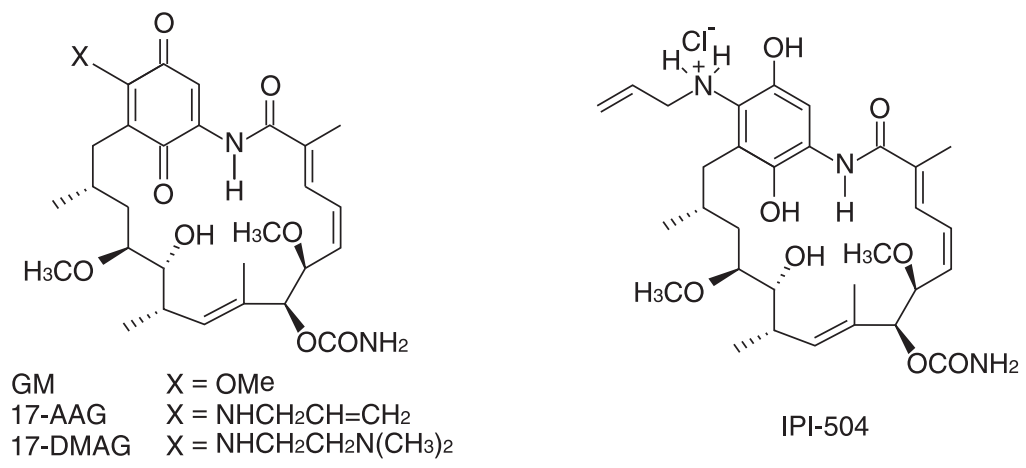

IPI-504<smiles>COc1c(C)cnc(Cn2cnc3c(Cl)nc(N)nc32)c1C</smiles>

CNF-2024/BIIB021<smiles>CCNC(=O)c1noc(-c2cc(C(C)C)c(O)cc2O)c1-c1ccc(CN2CCOCC2)cc1</smiles>

VER-52296NVP-AUY922<smiles>[X]O[C@H]1CC[C@H](NC2=C(C(N)=O)CCC(n3nc(C(F)(F)F)c4c3CC(C)(C)CC4=O)=C2)CC1</smiles>

SNX-5422 X $=\mathrm{COCH}_{2} \mathrm{NH}_{2}$ SNX-2122 X $=\mathrm{H}$

Figure 7 Chemical structures of Hsp90 inhibitors currently used in clinical evaluation with advanced cancers. ${ }^{80}$

17-AAG/tanespimycin and IPI-504/retaspimycin hydrochloride entered Phase 1 and Phase 2 clinical trials. 17-Dimethyaminoethylamino-17-demethoxy GA/alvespimycin is under clinical trials. IMC-225 (cetuximab/Erbit, a chimeric human-mouse monoclonal immunoglobulin G antibody), OSI-774 (elrotinib/Tarceva) and ZD1839 (gefnitib/iressa) are currently in Phase 2 and 3 development as single agents. ${ }^{75}$ IMC-225 blocks EGFR activation. OSI-774 and ZD1839 inhibit EGFR tyrosine kinase. The gefnitib/iressa unfortunately resulted in patient death. The combination strategies targeting angiogenesis through inhibition of the vascular endothelial growth factor receptor pathway (for example, bevacizumab combined with irinotecan) have demonstrated promising activity against several types of cancer. Tyrosine kinase inhibitors (gefnitib/iressa and erlotinib), platelet-derived growth factor receptor (PDGFR) inhibitors (imanitinib), mTOR inhibitors (termsirolimus and everrolimus), protein kinase $\mathrm{C}$ (PKC)- $\beta$ inhibitors, vascular endothelial growth factor receptor inhibitors and other angiogenesis pathway inhibitors (vatalanib and enzastaurin) are valuable anticancer agents. The suitable dose of these agents should be important to overcome side effects. Aberrant epigenetic gene regulation by histone deacetylation has been involved in tumorigenesis. Romidepsin is a potent HDAC inhibitor highly efficient in inhibiting HDAC activity at nanomolar concentrations. Romidepsin for the treatment of cutaneous T-cell lymphoma modulates targeting of cancer initiation and progression. Romidepsin approved by Food and Drug Administration is under clinical trials. ${ }^{76}$

\section{Anti-virus activity of Hsp90 inhibitor}

Hsp90 inhibitor BJ-B11 has an inhibitory effect on HSV-1 infection in vitro, and is thought as a candidate for clinical trials. ${ }^{77}$ The gyrase $\mathrm{B}$ inhibitor coumermycin Al inhibits HIV-1 integration and gene expression by inhibiting Hsp90 dimer formation. ${ }^{78}$ The HIV-1 Tat protein is secreted by infected cells. Hsp90 inhibitors abolish Tat entry into uninfected $\mathrm{T}$ cells and affect numerous biological responses such as apoptosis and cytokine secretion in several immune disorders during AIDS. ${ }^{79}$ Hsp90 inhibitors could be candidates for AIDS therapy.

\section{BENEFITS OF HSP9O INHIBITORS FOR CANCER THERAPY}

Genetic studies have provided evidence that multiple genetic changes occur in cancer cells. Therefore, anticancer agents targeting multiple proteins in cancer cells are compatible with cancer therapy. Hsp90 inhibitors target multiple client proteins involved in the malignancies of cancer cells. Mutant proteins are associated with Hsp90 function in cancer cell proliferation. Hsp90 inhibitors destabilize multiple mutant proteins associated with Hsp90 in cancer cells, inducing the cancer cells to undergo apoptosis or to differentiate into normal cells. The results are beneficial for cancer therapy in particular. However, Hsp90 biology is expanding beyond cancer science. Research on inflammation, autoimmune disease, diabetes, Parkinson's disease, hormonal imbalance and others is progressing in the field of Hsp90.

\section{SUPPLEMENTS}

\section{Outline of signaling-transduction pathways}

1. G-protein-coupled receptors.

2. Low-molecular-weight GTP binding protein.

3. Tyrosine kinase.

4. Ser/thr kinase.

5. Ion-channel receptors.

6. Nuclear pore (NP) channel.

7. Nuclear transcription factors. 
G-protein-coupled receptors. G-protein-coupled receptors have transmembrane domains that penetrate the plasma membrane seven times. The receptors include rhodopsin (a light sensor), hormone receptors, and nerve signaling and smell signaling receptors. The characteristic structure of a G-protein-coupled receptor is a trans-membrane domain consisting of a hydrophobic 25 -amino-acid repeat. $G$ protein is activated by GTP binding. The G-protein-GTP complex moves to the G-protein-GDP complex catalyzed by $G$ protein itself in the presence of GTPase-activating protein. The inactive G-protein-GDP complex progresses to the G-protein-GTP complex by guanine nucleotide exchange factor. The GTP binding proteins are classified into two groups consisting of those with three heterogeneous subunits $(\alpha, \beta$ and $\delta)$ and low-molecular-weight GTP binding proteins, such as Ras, Rho, Rac and Cdc42. G protein consists of three heterogeneous subunits. The $G$ protein dissociates into $G_{\alpha}$ and $G_{\beta \delta}$ complex through GTP binding to the $G_{\alpha}$ subunit. In mammalian species, 16 kinds of $\mathrm{G}_{\alpha}, 5$ kinds of $\mathrm{G}_{\beta}$ and 11 kinds of $\mathrm{G}_{\delta}$ genes are known. The mammalian $G_{\alpha}$ proteins have multiple roles in signaling pathways involving, for example, the regulation (activation or repression) of adenylcyclase, Rho guanine nucleotide exchange factor and the activation of cGMP phosphodiesterase and phospholipase $\mathrm{C}_{\beta}$. The activation of adenylcyclase generates the second messenger cAMP, which activates protein kinase $A$ (ser/thr kinase). The phospholipase $\mathrm{C}_{\beta}$ generates the second messengers phosphatidylinositol $\left(\mathrm{IP}_{3}\right)$, inositol 1,4,5-trisphosphate and diacylglycerol. Diacylglycerol activates PKC (ser/thr kinase) with $\mathrm{Ca}^{2+}$ released from the endoplasmic reticulum by $\mathrm{IP}_{3}$ binding to $\mathrm{IP}_{3}$ receptor on the endoplasmic reticulum. Calmodulin displays pleiotropic effects in the presence of $\mathrm{Ca}^{2+}$ (Figure 8). When CaM is occupied by two $\mathrm{Ca}^{2+}$ molecules, the $\mathrm{CaM}-\mathrm{Ca}^{2+}$ complex binds to myosin light-chain kinase (MLCK). The CaM$\mathrm{Ca}^{2+}$-MLCK complex phosphorylates myosin light chain (MLC). The phosphorylated MLC binds to actin molecule. The interaction of the phosphorylated MLC-actin complex with $\mathrm{Ca}^{2+}$-troponin induces muscle contraction. The CaM activates adenylcyclase, phosphorylase kinase, membrane $\mathrm{Ca}^{2+}, \mathrm{Mg}^{2+}$-ATPase, NDA kinase and CaM-dependent protein kinases, among others, in the presence of $\mathrm{Ca}^{2+}$. Thus, $\mathrm{G}$ protein affects multiple signaling pathways.

Tyrosine kinase receptor

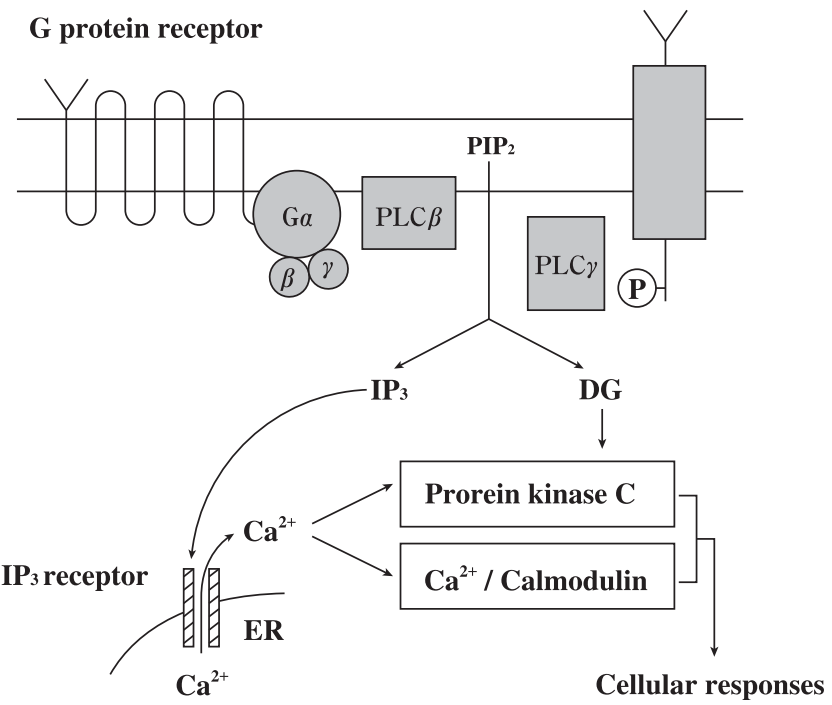

Figure 8 G-protein tyrosine kinase signaling pathway. DG: diacylglycerol; ER: endoplasmic reticulum; IP3: inositol 1,4,5-trisphosphate; PIP2: phosphatidylinositol 4,5-bisphosphate.
Low-molecular-weight GTP binding protein. The GTP binding proteins p21 (p20 p30 monomer) include Ras, Rho, Rab, Arf, Sar and Ran families. Ras was first identified as an oncogene. Ras is activated by several plasma membrane receptor signals. The activated Ras family proteins activate Raf kinase, which triggers the MAP (mitogenactivated protein $=$ microtubule-associated protein) kinase cascade. The downstream factors of Ras are sequentially Raf (MAPKKK), MAPK kinase 1, 2 (MAPKK) and ERK1, 2 (MAPK) (Figure 2). These kinases finally activate transcription factors such as Elk1, ternary complex factor and serum response factor. Ras-MAP signaling regulates gene expression, cell proliferation, differentiation and apoptosis. Rho family proteins are mainly involved in the regulation of actin filaments and the cytoskeleton arrangement, as well as cell division. Rab, Arf and Sar family proteins are involved in the regulation of protein translocation in the endoplasmic reticulum. Ran family proteins are involved in the regulation of RNA and protein transport into the nucleus. The MAPK group pathways include ERK/ MAPK, Janus kinase-signal transducers and activators of transcription, p38 MAPK and BMK1/ERK5 signaling pathways. The tyrosine kinase signaling pathways activate the Ras-MAP and Janus kinase-signal transducers and activators of transcription signaling pathways, among others. These factors are involved in the intracellular signaling induced by the stimulation of cytokines, hormones and growth factors.

Tyrosine kinase. Tyrosine kinase includes groups of both transmembrane receptor tyrosine kinase and membrane-associated tyrosine kinase.

Trans-membrane receptor tyrosine kinases: Trans-membrane receptor tyrosine kinases include the EGFR family, the fibroblast growth factor receptor family, the PDGFR family and the insulin receptor family. The fibroblast growth factor receptor family includes EGFR, ErbB-2, ErbB-3 and DER. The insulin receptor family includes insulin receptor, insulin-like growth factor receptor, Ros, Sea, Trk, Met, DILR, Sev and Ltk. The PDGFR family includes PDGFR $\alpha$, PDGFR $\beta$, colonystimulating factor 1 receptor, Kit, Ret and Flt. The fibroblast growth factor receptor family includes fibroblast growth factor receptor, Flg, Bek, K-Sam and Cek-1. When the trans-membrane is activated by extracellular signals, GTPase-activating protein, phospholipase $\mathrm{C}_{\beta}, \mathrm{IP}_{3}$ kinase and Raf- 1 bind together and exhibit their respective functions (Figure 8).

Non-trans-membrane receptor-type tyrosine kinases: Non-receptortype tyrosine kinases include the Src family and the Abl family of tyrosine kinases. The Src family tyrosine kinases are those associated with membranes, such as Src, Yes, Fgr, Lyn, Lck, Hck, Tkl, Blk, Dsrc 64 and Dsrc 24. The Abl family tyrosine kinases are localized in the cytoplasm or nucleus, such as Abl, Arg, Dash, Nabl, Fes/Fps and Fer. The Src family tyrosine kinases have Src homology domains SH1, SH2 and $\mathrm{SH}$. The SH1 domain is a tyrosine kinase domain itself located at the C-terminal region. The SH2 domain is involved in the proteinprotein interaction between phosphorylated tyrosine peptides. The $\mathrm{SH} 2$ and $\mathrm{SH} 3$ domains are closely related to proliferation, differentiation and tumorigenesis. The $\mathrm{SH} 2$ and $\mathrm{SH} 3$ domains have important roles in the signal-transduction pathway. The $\mathrm{SH} 2$ domain is involved in the interaction between the ErbB receptor tyrosine kinase and $\mathrm{PI} 3 \mathrm{~K} . \mathrm{IP}_{3}$ interacts with the pleckstrin homology domain of Akt/PKB and activates Akt/PKB.

Hsp90 inhibitor decreases Hsp90-pp60v-Src complex: Hsp90 specifically forms a complex with pp60v-Src, and the pp60v-Src/Hsp90 complex is unable to function as a protein tyrosine kinase. When pp60v-Src is subsequently found inserted into plasma membrane, it is 
active as a kinase is no longer associated with Hsp90. ${ }^{80}$ Benzoquinoid ansamycins suppress the phosphorylation of Src in v-Src-transformed cells. ${ }^{81}$ Wild-type $\mathrm{v}$-Src expression regulates c-Src kinase activity through a direct interaction between $\mathrm{v}$-Src and $\mathrm{c}-\mathrm{Src}$, inducing the hyper-phosphorylation of c-Src $\mathrm{Tyr}^{416.82}$ A C-terminal peptide containing c-Src-Tyr ${ }^{527}$ is deleted in v-Src. ${ }^{83}$ When Fyn-Tyr ${ }^{531}$ corresponding to c-Src-Tyr ${ }^{527}$ is deleted, NIH3T3 cells are transformed. This result indicates that the phosphorylation of Fyn-Tyr ${ }^{531}$ and c-Src-Tyr ${ }^{527}$ is indispensable for the cells to have a normal status. ${ }^{83}$ The substitution of phenylalanine for Try ${ }^{416}$ in c-Src suppresses the biological activity of the mutant proteins as assayed using colony formation using soft agar and the induction of morphological alterations. These results suggest that the phosphorylation of $\mathrm{Tyr}^{416}$ has a positive regulatory effect on the activity of the protein tyrosine kinase pp60c-Src. ${ }^{84}$ The phosphorylation of $\mathrm{Tyr}^{416}$ and $\mathrm{Tyr}^{527}$ of c-Src in NIH3T3 cells has been reported to regulate cell proliferation and cell-to-cell communication. ${ }^{85}$ These results indicate that the phosphorylations of $\mathrm{Tyr}^{416}$ and $\mathrm{Tyr}^{527}$ exert positive and negative effects on c-Src tyrosine kinase activity, respectively.

Ser/thr kinases. Protein kinase $\mathrm{A}, \mathrm{PKC}, \mathrm{PKB} / \mathrm{Akt}$ and protein kinase $\mathrm{G}$ are activated by cAMP, diacylglycerol and $\mathrm{Ca}^{2+}$ in the $\mathrm{IP}_{3}$ signaling pathway, PI $(3,4) \mathrm{P}_{2}$ and cGMP, respectively. Na diuretic peptide ligands such as A-type natriuretic peptide, B-type natriuretic peptide and C-type natriuretic peptide stimulate the GC receptor. The GC activated by nitrogen oxide generated by nitrogen oxide synthetase is activated by $\mathrm{Ca}^{2+}$ bound to $\mathrm{CaM}$ in the nerve signaling pathway. CaM-dependent protein kinase II is activated by $\mathrm{Ca}^{2+}$ bound to CaM. MAPK and Cdc2 phosphorylate serine, threonine and tyrosine residues (Figure 8).

Ion-channel receptors. The ion-channel receptors are classified into two groups. The cation-channel receptors for acetylcholine, glutamate, serotonin and ATP selectively transport $\mathrm{Na}^{+}, \mathrm{K}^{+}$and $\mathrm{Ca}^{2+}$, and the anion-channel receptors for glycine and GABA selectively transport $\mathrm{Cl}^{-}$. The nerve signal-transduction substances, other than glycine, act on G-protein-coupled receptors as well as ion-channel receptors. The nicotin-dependent acetylcholine receptor is a trans-membrane receptor with four domains consisting of five subunits, and the 20 domains work as one ion channel. Over 10 subunits of glutamate receptor channels are known. $N$-methyl-D-aspartate, $\alpha$-amino-3-hydroxy-5methyl-4-isoxazole-propionic acid and kinic acid receptors are formed using combinations of these subunits. The glutamate receptors have important roles in the nerve signal-transduction pathways, for example, the plasticity of synapse transduction in the hippocampus, cerebellum, memory and highly organized nerve functions of the brain. NP in the nuclear membrane consisting of the inner and outer membrane has a diameter of $100 \mathrm{~nm}$. Protein with an MW of $20 \sim 40 \mathrm{kDa}$ is permeable through the NP. The NP is enclosed by a caged structure of large protein complexes, and NP channel transports RNA and proteins.

NP channel. Proteins containing a nuclear localization signal are imported into the nucleus. The export mechanism of RNA, such as mRNA and low-molecular-weight RNA, is not clear yet. The cap structure of mRNA is known to be important for its export, and the Rev of HIV and the Rex of HTLV-I are essential for export.

Nuclear transcription factors. Transcription factors are imported from the cytoplasm and localized in the nucleus. Ets, Fos, Jun, Maf, Myb, Myc, Rel and Ski are important transcription factors involved in transcription activation or regulation. Nuclear factor- $\kappa \mathrm{B}$ consists of the hetero-subunits p50 and p65 (Rel). I $\mathrm{kB}$ associates with nuclear factor- $\kappa \mathrm{B}$ negatively, regulating the nuclear translocation of nuclear factor- $\kappa \mathrm{B}$. The hetero-dimer Fos/Jun (p38/p34) complex is a constituent of activator protein-1, which is regulated by PKC. Ets (avian retrovirus E26 transformation specific), fos (FBJ mouse osteosarcoma), jun (avian sarcoma virus 17), maf (musculo aponeurotic fibrosarcoma), $m y b$ (avian myeloblastosis virus), myc (avian myelocytomatosis MC29 virus), rel (avian retrovirus) and ski (avian leukemia virus/Sloan-Kettering Institute) are oncogenes.

Some of the transcription factors involved in oncogene function are described.

1 Chen, B., Piel, W.H., Bruford, E. \& Monterio, A. The HSP90 family of genes in the human genome: insights into their divergence and evolution. Genomics 86, 627-637 (2005).

2 Caldenwood, S. K., Khaleque, M. A., Sawyer, D. B. \& Ciocca, D.R. Heat shock proteins in cancer: chaperones of tumorigenesis. Trends Biochem. Sci. 31, 164-167 (2006).

3 Bedin, M., Gaben, A. M., Saucier, C. \& Mester, J. Geldanamycin, an inhibitor of the chaperone activity of HSP90, induces MAPK-independent cell cycle arrest. Int. J. Cancer 109, 643-652 (2004).

4 Whitesell, L., Mimnaugh, E. G., De Costa, B., Myers, C. E. \& Neckers, L. Inhibition of heat-shock protein HSP90-pp60v-src hetero-protein complex formation by benzoquinoid ansamycins. Proc. Natl. Acad. Sci. USA 91, 8324-8328 (1994).

5 Stebbins, C. E. et al. Crystal structure of an Hsp90-geldanamycin complex: targeting of a protein chaperone by an antitumor agent. Cel/ 89, 239-250 (1997)

6 Pearl, L. H., Prodromou, C. \& Workman, P. The Hps90 molecular chaperone: an open and shut case for treatment. Biochem. J. 15, 439-453 (2008).

7 Ratzke, C., Mickler, M., Hellenkamp, B., Buchner, J. \& Hugel, T. Dynamics of heat shock protein $90 \mathrm{C}$-terminal dimerization is an important part of its conformational cycle. Proc. Natl. Acad. Sci. USA 107, 16101-16106 (2010).

8 Hawle, P. et al. The middle domain of hsp90 acts as a discriminator between different types of client proteins. Mol. Cell. Biol. 26, 8385-8395 (2006).

9 Soti, C., Racz, A. \& Csermely, P. A nucleotide-dependent molecular switch controls ATP binding at the $\mathrm{C}$-terminal domain of Hsp90. N-terminal nucleotide binding unmasks a C-terminal binding pocket. J. Biol. Chem. 277, 7066-7075 (2002).

10 Harris, K. F., Christensen, J. B., Radany, E. H. \& Imperiale, M. J. Novel mechanisms of $\mathrm{E} 2 \mathrm{~F}$ induction by $\mathrm{BK}$ virus large-T antigen: requirement of both the $\mathrm{pRb}$-binding and the J domains. Mol. Cell. Biol. 18, 1746-1756 (1998).

11 Gray-Bablin, J. et al. A redundant cyclin in breast cancer. Proc. Natl. Acad. Sci. USA 95, 15215-15220 (1996).

12 Rustgi, A. K., Dyson, N. \& Bernards, R. Amino-terminal domains of c-myc and N-myc proteins mediate binding to the retinoblastoma gene products. Nature $352,541-544$ (1991).

13 Gomez-Roman, N., Grandori, C., Eisenman, R. N. \& White, R. J. Direct activation of RNA polymerase III by c-Myc. Nature 421, 290-294 (2003).

14 Yamaki, H. et al. Inhibition of the association with nuclear matrix of pRB, p70 and p40 proteins along with the specific suppression of C-MYC expression by geldanamycin and herbimycin, antibiotics of ansamycin group. J. Antibiot 49, 1021-1026 (1995).

15 Yamaki, H., Iguchi-Ariga, S. M. \& Ariga, H. Inhibition of c-myc gene expression in murine lymphoblastoma cells by geldanamycin. J. Antibiot 42, 604-610 (1989).

16 Grandori, C. et al. c-Myc binds to human ribosomal DNA and stimulates transcription of rRNA genes by RNA polymerase I. Nat. Cell Biol. 7, 311-318 (2005).

17 Felton-Edkins, Z. A. et al. Direct regulation of RNA polymerase III by RB, p53 and c-Myc. Cell Cycle 2, 181-184 (2003).

18 Iguchi-Ariga, S. M. et al. An initiation site of DNA replication with transcriptional enhancer activity present upstream of the c-myc gene. EMBO J. 7, 3134-3142 (1988).

19 Zamore, P. D. \& Haley, B. Ribo-gnome: the big world of small RNAs. Science 309, 1519-1524 (2005).

20 Bueno, M. J., Perez de Castro, I. \& Malumber, M. Control of cell proliferation pathways by microRNAs. Cell Cycle 7, 3134-3148 (2008).

21 Reimer, D., Sadr, S. \& Wiedemair, A. Expression of the E2F family of transcription factors and its clinical relevance in ovarian cancer. Ann. N. Y. Acad. Sci. 1091, 270-281 (2006).

22 Christoffersen, N. R. et al. p53-independent upregulation of miR-34a during oncogeneinduced senescence represses MYC. Cell Death Differ. 17, 236-245 (2010).

23 Akao, Y., Nakagawa, Y. \& Naoe, T. let-7 microRNA functions as a potential growth suppressor in human colon cancer cells. Biol. Pharm. Bull. 29, 903-906 (2006).

24 Pare, J. M. et al. Hsp90 regulates the function of agronate 2 and its recruitment to stress granules and P-bodies. Mol. Biol. Cell 20, 3273-3284 (2009).

25 Carystinos, G. D., Kandouz, M., Alaoul-Jamali, M. A. \& Batist, D. Unexpected induction of the human connexin 43 promoter by the ras signaling pathway is mediated by a novel putative promoter sequence. Mol. Pharmacol. 63, 821-831 (2003). 
26 Chiarugi, V. \& Ruggiero, M. Role of three cancer 'master gene' p53, bcl2 and c-myc on the apoptotic process. Tumori 82, 205-209 (1996).

27 Miyata, Y., Ikawa, Y., Sibuya, M. \& Nishida, E. Specific association of a set of molecular chaperones including HSP9O and Cdc37 with MOK, a member of the mitogenactivated protein kinase superfamily. J. Biol. Chem. 276, 21841-21848 (2001).

28 Miyata, Y. \& Nishida, E. CK2 controls multiple protein kinases by phosphorylating a kinase-targeting molecular chaperone, Cdc37. Mol. Cell. Biol. 24, 4065-4074 (2004).

29 Price, G. B. et al. Identification of a cis-element that determines autonomous DNA replication in eukaryotic cells. J. Biol. Chem. 278, 19649-19659 (2003).

30 Di Paola, D., Price, G. B. \& Zannis-Hadjopoulos, M. Differentially active origins of DNA replication in tumor versus normal cells. Cancer Res. 66, 5094-5103 (2006).

31 Yamaki, H., Suzuki, H., Choi, E. C. \& Tanaka, N. Inhibition of DNA synthesis in murine tumor cells by geldanamycin, an antibiotic of the benzoquinoid ansamycin. J. Antibiot 35, 886-892 (1982).

32 Ozaki, A. et al. Complex formation between lamin A and the retinoblastoma gene product. Oncogene 9, 2649-2653 (1994).

33 McCabe, M. T., Davis, J. \& Day, M. L. Regulation of DNA methyltransferase 1 by the pRb/E2F pathway. Cancer Res. 65, 3624-3632 (2005).

34 Zhou, Q., Agoston, A. T., Atadja, P., Nelson, W. G. \& Davidson, N. E. Inhibition of histone deacetylases promotes ubiquitin-dependent proteasomal degradation of DNA methyltransferase 1 in human breast cancer cells. Mol. Cancer Res. 6, 873-883 (2008).

35 Hellebreakers, D. M. et al. Angiostatic activity of DNA methytransferase inhibitors. Mol. Cancer Ther. 5, 467-475 (2006).

$36 \mathrm{Li}, \mathrm{C}$. et al. The critical role of the PE21 element in oncostatin M-mediated transcriptional repression of the p53 tumor suppressor gene in breast cancer cells. Oncogene 20, 8193-8220 (2001).

37 Jung, P., Menssen, A., Meyr, D. \& Hermeking, H. Ap4 encodes a c-Myc-inducible repressor of p21. Proc. Natl. Acad. Sci. USA 105, 15046-15051 (2008).

38 Sain, N. et al. Potentiation of pacitaxel activity by HSP90 inhibitor 17-allylamino17-demethoxygeldanamycin in human ovarian carcinoma cell lines with high levels of activated AKT. Mol. Cancer Ther. 5, 1197-1208 (2006).

39 Maloney, A. et al. Gene and protein expression profiling of human ovarian cancer cells treated with heat shock protein 90 inhibitor17-allylamino-17-demethoxygeldanamycin. Cancer Res. 67, 3239-3253 (2007).

40 Nobuhisa, T. et al. Translocation of heparanase into nucleus results in cell differentiation. Cancer Sci. 98, 535-540 (2007).

41 Huston, A. et al. Targeting Akt and heat shock protein 90 produces synergistic multiple myeloma cell toxicity in the bone marrow microenvironment. Clin. Cancer Res. 14, 865-874 (2008).

$42 \mathrm{Koll}, \mathrm{T}$. T. et al. HSP90 inhibitor, DMAG, synergizes with radiation of lung cancer cells by interfering with base excision and ATM-mediated DNA repair. Mol. Cancer Ther. 7 1985-1992 (2008).

43 Tsutsumi, S. et al. A small molecule cell-impermeant Hsp90 antagonist inhibits tumor cell mobility and invasion. Oncogene 27, 2478-2487 (2008).

44 Soga, S. et al. KF25706, a noveloxime derivative of radicicol, exhibits in vivo antitumor activity via selective depletion of HSP90 binding signaling molecules. Cancer Res. 59, 2931-2938 (1999).

45 Ikuina, Y. et al. Synthesis and antitumor activity of novel O-carbamoylmethyloxime derivatives of radicicol. J. Med. Chem. 46, 2534-2541 (2003).

46 Martin, C. J. et al. Molecular characterization of macbecin as an Hsp90 inhibitor. J. Med. Chem. 51, 2853-2857 (2008).

47 Zhang, M. Q. et al. Optimizing natural products by biosynthetic engineering: discovery of nonquinone Hsp90 inhibitors. J. Med. Chem. 51, 5494-5497 (2008).

48 Chandralpaty, S. et al. SNX2112, a synthetic heat shock protein 90 inhibitor, has potent antitumor activity against HER kinase-dependent cancers. Clin. Cancer Res. 14, 240-248 (2008).

49 Okawa, Y. et al. SNX2112, a selective Hsp90 inhibitor, potently inhibits tumor cell growth, angiogenesis, and osteoclastogenesis in multiple myeloma and hematologic tumors by abrogating signaling via Atk and ERK. Blood 113, 846-855 (2009).

50 Song, D. et al. Antitumor activity and molecular effects of the novel heat shock protein 90 inhibitor, IPI-504, in pancreatic cancer. Mol. Cancer Ther. 7, 3275-3284 (2008).

51 Akiyama, T. et al. Genestein, a specific inhibitor of tyrosine-specific protein kinase. J. Biol. Chem. 262, 5592-5595 (1987).

52 Basak, S., Pookot, D., Noonan, E. J. \& Dahiya, R. Genestein down-regulates androgen receptor by modulating HDAC6-Hsp90 chaperone function. Mol. Cancer Ther. 7, 3195-3202 (2008).

53 Jeong, J. H., An, J. Y., Kwon, Y. T., Li, L. Y. \& Lee, Y. J. Quercetin-induced ubiquitination and down-regulation of Her-2/neu. J. Cell Biochem. 105, 585-595 (2008).

$54 \mathrm{Wu}, \mathrm{L}$. X. et al. Disruption of the Bcr-Abl/Hsp90 protein complex: a possible mechanism to inhibit Bcr-Abl positive human leukemic blasts by novobiocin. Leukemia 22, 1402-1409 (2008).

55 Donelly, A. \& Blagg, B. S. Novobiocin and additional inhibitors of the Hsp90 C-terminal nucleotide-binding pocket. Curr. Med. Chem. 15, 2702-2717 (2008).
56 Radanyi, C. et al. Antiproliferative and apoptotic activities of tosylcyclonovobiocic acids as potent heat shock protein 90 inhibitors in human cancer cells. Cancer Lett. 274, 88-94 (2009).

57 Lin, T. Y. et al. The novel Hsp90 inhibitor STA-9090 exhibits activity against Kit-dependent and -independent malignant mast cell tomors. Exp. Hematol. 36, 21266-21277 (2008)

58 Sharp, S. Y. et al. Inhibition of heat shock protein 90 molecular chaperone in vitro and in vivo by novel, synthetic, potent resorcinylic pyrazol/isoxazole amide analogues. Mol. Cancer Ther. 4, 1198-1211 (2007).

59 Eccles, S. A. et al. NVP-AUY922: a novel heat shock protein 90 inhibitor active against xenograft tumor growth, angiogenesis, and metastasis. Cancer Res. 66, 2850-2860 (2008).

60 Caldas-Lopes, E. et al. Hsp90 inhibitor PU-H71, a multimodal inhibitor of malignancy, induces complete responses in triple-negative breast cancer models. Proc. Natl. Acad. Sci. USA 106, 8367-8373 (2009).

61 Bao, R. et al. CUDC-305, a novel synthetic HSP90 inhibitor with unique pharmacologic properties for cancer therapy. Clin. Cancer Res. 15, 4046-4057 (2009).

62 Zhang, H. et al. BIIB021, a synthetic HSP90 inhibitor, has broad application against tumors with acquired multidrug resistance. Int. J. Cancer 126, 1226-1234 (2010).

63 Boll, B. et al. Heat shock protein 90 inhibitor BIIB021 (CNF2024) depletes NF-kappa $B$ and sensitizes Hodgkin's lymphoma cells for natural killer cell-mediated cytotoxicity. Clin. Cancer Res. 15, 4046-4057 (2009).

64 McMillin, D. W. et al. Antimyeloma activity of the orally bioavailable dual phosphatidylinositol 3-kinase/mammalian target of rapamycin inhibitor NVP-BEZ235. Cancer Res. 69, 5835-5842 (2009).

65 Lang, S. A. et al. Targeting heat-shock protein 90 improve efficacy of rapamycin in a model of hepatocellular carcinoma in mice. Hepatology 49, 523-532 (2009).

66 Shulte, T. W., Blugosklonny, M. V., Ingui, C. \& Neckers, L. Disruption of the Raf-1Hsp90 molecular complex results in destabilization of Raf-1 and loss of Raf-1-Ras association. J. Biol. Chem. 270, 28654-28659 (1995).

67 Engelman, J. A. et al. Effective use of PI3K and MEK inhibitors to treat mutant Kras G12D and PIK3CA H1047R murine lung cancer. Nat. Med. 14, 1315-1316 (2008).

68 Fujita, N., Sato, S., Ishida, A. \& Tsuruo, T. Involvement of Hsp90 in signaling and stability of 3-phosphoinositide-dependent kinase-1. J. Biol. Chem. 277, 10346-10353 (2002).

69 Chandralpaty, S. et al. Inhibitors of Hsp90 block p95-Her2 signaling in trastuzumabresistant tumors and suppress their growth. Oncogene 29, 325-334 (2010).

70 Leow, C. C. et al. Antitumor efficacy of IPI-504, a selective heat shock protein 90 inhibitor against human epidermal growth factor receptor 2-positive human xenograft models as a single agent and in combination with trastuzumab or lapatinib. Mol. Cancer Ther. 8, 2131-2141 (2009).

$71 \mathrm{Hu}, \mathrm{X}$. F. et al. PIM-1-specific mAb suppresses human and mouse tumor growth by decreasing PIM-1 levels, reducing Akt phosphorylation, and activating apoptosis. J. Clin. Invest. 119, 362-376 (2009).

72 Imada, T. et al. Cox-2 induction by heparanase in the progression of breast cancer. Int. J. Mol. Med. 17, 221-228 (2006).

73 Nakajima, M. et al. Suramin, a potent inhibitor of melanoma heparanase and invasion. J. Biol. Chem. 266, 9661-9666 (1991).

74 Taldone, T., Gozman, A., Maharaj, R. \& Chiosis, G. Targeting Hsp90: small molecule inhibitors and their clinical development. Curr. Opin. Pharmacol. 8, 370-374 (2008).

75 Ciardiello, F., De Vita, F., Ordituara, M., De Piasido, S. \& Tortora, G. Epidermal growth factor receptor tyrosine kinase inhibitors in late stage clinical trials. Expert Opin. Emerg. Drugs 8, 501-514 (2003).

76 Campas-Moya, C. Romidepsin for the treatment of cutaneous T-cell lymphoma. Drugs Today 45, 787-795 (2009)

$77 \mathrm{Ju}, \mathrm{H}$. Q. et al. Synthesis and in vitro anti-HSV-1 activity of a novel Hsp90 inhibitor BJ-B11. Bioorg. Med. Chem. Lett. 21, 1675-1677 (2011).

78 Vozzolo, L. et al. Gyrase, B inhibitor impairs HIV-1 replication. Curr. Opin. Invest. Drugs 9, 1287-1295 (2008).

79 Vendeville, A. et al. HIV-1 Tat enters T cells using coated pits before translocating from acidified endosomes and eliciting biological responses. Mol. Biol. Cell 15, 2347-2360 (2004).

$80 \mathrm{Xu}, \mathrm{Y}$. \& Lindquist, S. Heat-shock protein HSP90 governs the activity of pp60v-src kinase. Proc. Natl. Acad. Sci. USA 90, 7074-7078 (1993).

81 Uehara, Y., Hori, M., Takeuchi, T. \& Umezawa, H. Phenotypic change from transformed to normal by benzoquinoid ansamycins accompanies inactivation of p60src in rat kidney cells infected with Raus sarcoma virus. Mol. Cell. Biol. 6, 2198-2206 (1986).

82 Vojtechova, M., Senigl, F., Sloncova, E. \& Tuhachova, Z. Regulation of c-Src activity by the expression of wild-type $\mathrm{V}$-Src and its kinase-dead double Y416F-K295N mutant. Arch. Biochem. Biophys. 455, 136-143 (2006).

83 Cooper, J. A. The Src Family of Protein-Tyrosine Kinases. in Peptides and Protein Phosphorylation (ed. Kemp, B. E.) 85(CRC Press, Boca Raton, FL, 1991).

84 Ferracini, R. \& Brruge, J. Analysis of mutant forms of the c-src gene product containing a phenylalanine substitution for tyrosine 416. Oncogene Res. 5, 205-219 (1990).

85 Azarnia, R., Reddy, S., Kmiecik, T. E., Shalloway, D. \& Loewenstein, W. R. The cellular src gene product regulates junctional cell-to-cell communication. Science 239, 396-401 (1988). 